\title{
Urgences
}

\section{Deux chansons sur les choses}

\section{Jean-Marc Cormier}

Numéro 8, 4e trimestre 1983

Littérature jeunesse

URI : https://id.erudit.org/iderudit/025119ar

DOI : https://doi.org/10.7202/025119ar

Aller au sommaire du numéro

Éditeur(s)

Urgences

ISSN

0226-9554 (imprimé)

1927-3924 (numérique)

Découvrir la revue

Citer ce document

Cormier, J.-M. (1983). Deux chansons sur les choses. Urgences, (8), 49-52.

https://doi.org/10.7202/025119ar

Ce document est protégé par la loi sur le droit d'auteur. L'utilisation des services d'Érudit (y compris la reproduction) est assujettie à sa politique d'utilisation que vous pouvez consulter en ligne.

https://apropos.erudit.org/fr/usagers/politique-dutilisation/
Cet article est diffusé et préservé par Érudit.

Érudit est un consortium interuniversitaire sans but lucratif composé de l’Université de Montréal, l'Université Laval et l'Université du Québec à Montréal. Il a pour mission la promotion et la valorisation de la recherche. https://www.erudit.org/fr/ 


\section{JEAN-MARC CORMIER}

\section{Deux chansons sur les choses}




\section{LES VOYAGES D'UN ARBRE}

Un arbre dans ses branches

Accueille aujourd'hui deux oiseaux

Un arbre se balance

Heureux de ses amis nouveaux

Sa cime s'illumine

Lorsque le soleil du matin

Le coeur en fête fier d'apparaître

Se lève dans I'horizon lointain

Un arbre chante et danse

Le vent siffle sa mélodie

Un arbre se balance

Puisqu'il est tout à sa folie

"Gentilles hirondelles

Petits oiseaux doux tourtereaux

Chantez la vie est belle

Abritez-vous sous mes rameaux

Prenez de mes brindilles

Pour construire chez-moi votre nid Créatures gentilles

Sentez mes fleurs mangez mes fruits

Dans vos vagabondages

Vous-mêmes vous me servirez

Au cours de vos voyages

C'est moi que vous transporterez

Dans vos vagabondages

Vous-mêmes vous me servirez

Au cours de vos voyages

C'est moi que vous transporterez" 


\section{C'EST POUR REVENIR}

La rivière s'en va

Mais c'est pour revenir

Elle rejoint le fleuve

Et ils s'en vont mourir

Quelque part dans la mer

Mais c'est pour revenir

Le printemps est parti

Mais c'est pour revenir

L'automne lui aussi

$\mathrm{Ne}$ peut que revenir

Toutes les feuilles sont tombées

Tout a l'air de mourir

Mais I'hiver va passer

Et tout va refleurir

La rivière $s$ 'en va

Mais c'est pour revenir

Elle rejoint le fleuve

Et ils s'en vont mourir

Quelque part dans la mer

Mais c'est pour revenir

Nos parents nos amis

Finissent tous par partir

Un jour on part aussi

Mais c'est pour revenir

Le fleuve de la vie

Nous entraîne à mourir Mais la nature nous dit Que c'est pour revenir

La rivière s'en va Mais c'est pour revenir

Elle rejoint le fleuve

Et ils s'en vont mourir

Quelque part dans la mer

Mais c'est pour revenir. 


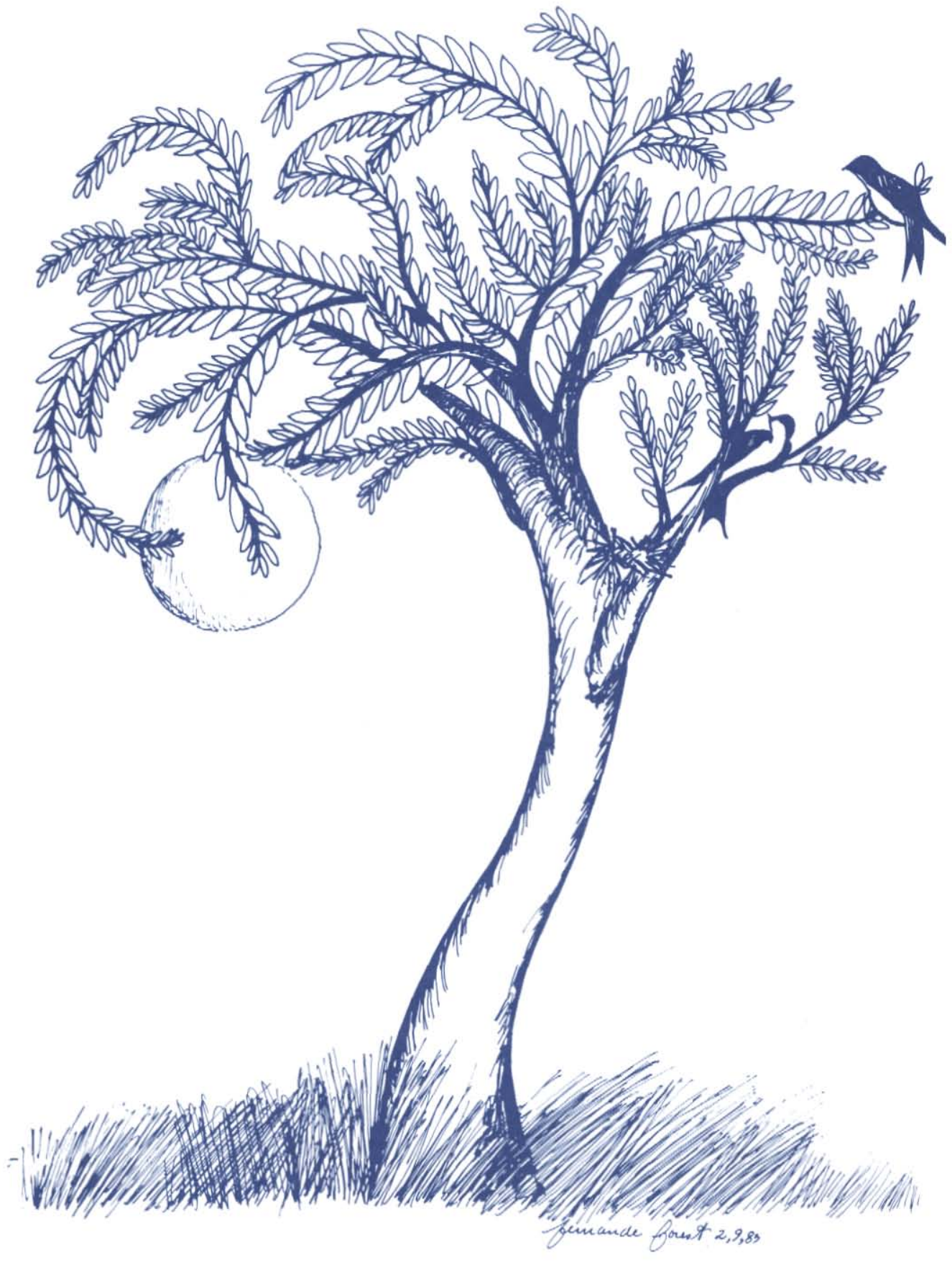

